\section{Faust, the burst forth the career and publication ethics}

\author{
Alberto Pastore
}

In my opinion, it is rewarding for all of us to observe how our community of Italian management scholars has significantly evolved in recent years.

Breaking free from the academic logic that ruled in the past, we have set up SIMA, our own representative and democratically elected scientific society of Italian management scholars; we have identified the values in which we recognize ourselves: openness, rigour, relevance, dissemination, ethics; we have nurtured a new organizational culture devoted to participation and service for the benefit of the scientific community; we have contributed, in a decisive manner, to configuring the newly expanded governance design of scientific societies in Italy dealing with accounting, management and organization studies. In this redesigning process, the AIDEA (Italian Academy of Economia Aziendale) was given a new role as the official representative with the responsibility of relating with institutions, professional bodies, and policymakers.

Within the institutional context, among other achievements, we have attained the formal recognition of the non-bibliometric nature of our discipline and the establishment of a dedicated organizational framework (GEV 13B) for the evaluation of research in the field of business studies.

As regards the Italian community of management scholars, we have exponentially improved our ability to fulfil rigorous and relevant research. Our scientific production standards have grown dramatically, placing our community in a prominent position not only among business disciplines but within the extensive area of economics and statistics studies (Area 13). Now we are fully participating in the scientific debate at an international level by collaborating and interacting with the most important scientific organizations worldwide. Our journals are firmly aligned with this international perspective, as underlined by the recent acceptance of Sinergie Italian Journal of Management in Scopus.

We have taken on the responsibility of leading the training of future generations and the life-long training of the managerial class; we have enhanced our connections with business companies, and we are leading in universities' third mission and public engagement activities, as well as in management and service activities for our own universities.

While being pleased about this, we cannot forget that there are some very important issues that remain unsolved, as well as new emerging issues. Among these pending issues, the following stand out for their relevance: the matters of the value of research and the enhancement of its results; the search for the complete adequacy of evaluation and selection systems; respect for ethical principles in our profession, research and publication. The SIMA positioning paper "Job and career of the Management scholar"
Alberto Pastore

Faust, the burst forth the

career and publication ethics 
sinergie Vol. 39, Issue 2, 202

focuses on these topics, among others, and can be retrieved for further information at www.societamanagement.it.

Regarding the first point, the value of research and the enhancement of its results, if we agree - and frankly it seems hard not to do so - that the ultimate purpose of our work is to create value for society and the economy, this means that when we carry out research we should produce studies and publications that have a tangible impact for the business environment and society, thus generating knowledge as a competitive resource. Therefore, we must critically reflect both on the contents and objectives of our research and on the channels and terms we use to disseminate our results. Within such a context, the risk of locking ourselves in the ivory tower and becoming autoreferential is very likely.

The second critical point concerns the adequacy of evaluation and selection systems, which represents a major issue. Here we must limit ourselves to underlining that the current systems in place are strongly unbalanced in favor of the dimension of research, to the detriment of other areas of the academic profession. With specific reference to the selection of professors at the Italian national qualification level - and even more so at the local level - the following burning questions emerge: How can a scholar's be awarded in the absence of a teaching evaluation? How can a candidate's research capacity be evaluated without discussing his or her scientific titles?

The third aspect involves respect for ethical principles in the profession, research and publication. Our scientific society SIMA has issued its own Code of Ethics, referring to the general aspects of the management professor's activity that all us SIMA Associates are required to adhere to (we hereby suggest all members to carefully read the Code of Ethics).

Here, we will further explore our reflection on ethics applied to research and publication. It is a topic that has become increasingly relevant in recent times, leading the AIDEA to publish a brief note on "Ethics, Integrity and Responsibility of Authors in Publications".

Let us consider the main critical issues on this matter by adopting the researcher's perspective.

The first case concerns data falsification, which is about the collection of data and their manipulation to demonstrate a preconceived thesis. This behavior must be severely penalized, as it undermines the truthfulness of the results not only in the specific study at hand, but also in the stream of research that originates from it.

Another critical issue is plagiarism, which is a form of misappropriation of intellectual property. In our case, plagiarism consists in the use of ideas or portions of other scholars' research output without authorization or failing to quote the original reference.

Duplicate publications can be assimilated to a form of self-plagiarism, i.e. the use of the same output / article in different publications, with or without relative references. This is on the same level of redundant publications, which replicate existing publications by recycling their hypotheses, results and conclusions, and simply integrating them by expanding the processed data. Both duplicate and redundant publications are considered unethical practices, as they infringe copyright law, "inflate" 
the curricular credentials of authors, and bring confusion to the scientific community.

An extremely relevant and current issue concerns the potential distortion of selection and publication processes due to convergence or conflict of interest. Being part of an interest group - of evaluators and evaluated, clients, editors, reviewers and authors - and the presence of public and private conflicts of interest can produce alterations in decisionmaking processes inherent to the evaluation process. The consequences can be extremely serious both in terms of the incorrect consideration of real research quality and the dissemination of scientific results that are not adequately validated, as well as in terms of an unfair evaluation of researchers' profiles, especially when their careers and possibilities of promotion are under assessment.

Another important aspect to consider is so-called "authorship", i.e. the correct identification of authors who really contributed to a research project. As clearly highlighted in the aforementioned AIDEA document, some incontrovertible data reveal the emergence of problems such as the abnormal growth in the number of publications per single author and that of the number of authors per single publication. From an ethical point of view, the phenomena of "gift authorship", as well as the multiplication and cross-subsidization of the signatures of publications, must be clearly avoided since these behaviours determine a falsification of researchers' quality and scientific productivity. Furthermore, a single author's intellectual and organizational contribution should exceed a minimum reasonable threshold for it to be included among the authors of a scientific product.

The choice of publication channel may also have ethical implications. As underlined in the SIMA positioning paper, the publication of research results must occur through channels characterized by transparency, seriousness, and professionalism. As far as scientific journals are concerned, it is strongly desirable to avoid publication in so-called "predatory journals". Characterized by absent or unclear "aim \& scope" sections, predatory journals operate with poor transparency, publish an exaggerated number of articles without carrying out an adequate selection and peer review procedure, and require significant financial contributions for submission and/or publication.

This examination of ethical principles applied to research and publication is certainly not exhaustive. Still, we believe it is enough, in the present context of discussion, to lead us to the concluding reflections of this editorial, labelled under the provocative title "Faust, the burst forward in careers and publications ethics".

The Italian research evaluation system (VQR) and the scholarly evaluation system for career development purposes (ASN and local public exam) in place have taken on their own (perfectible!) connotations, and in these contexts the competitive dynamics among applicants have become increasingly strong. The tool of ASN median values that positively stimulated productivity in the academic community at the beginning, now manifests its intrinsic degeneration by projecting the threshold 
sinergie Vol. 39, Issue 2, 202

of acceptance higher and higher, thus causing a potentially endless "quantitative" run-up, despite the quality and relevance of research.

However, the current fierce and sometimes distorted competition can lead researchers to obtain publications "for career purposes only". This approach can cause highly harmful effects such as, for example, research with little relevance, research results that are not properly disseminated, the neglect of other dimensions of the profession (in particular teaching, but also third mission and service activity). Above all, the exertion of strong "contextual" pressures on morally less solid subjects can induce some researchers to approach unethical practices, such as those described above, in order to improperly and only apparently strengthen their scientific curricular profile.

In these cases, we want to specify the unethical and sometimes illegal profile of certain behaviours, which produce the effect of disowning meritocracy, harming our community and, when brought to evidence, directly harming the person concerned. In Goethe's literary work, the protagonist Faust, a scholar of philosophy and science, sells his soul to Mephistopheles to obtain even greater power, youth and knowledge. Playing with the metaphor, we hope that no management scholar will be tempted to follow Faust's example and that good research and publications that are rigorous, relevant and useful and are produced following ethical principles will always prevail.

The ethical sense of research and publication must be a solid and founding principle of our scientific community. From this perspective, our Sinergie - Italian Journal of Management is strongly committed to the affirmation of this principle.

\section{Academic or professional position and contacts}

\section{Alberto Pastore}

Co-Editor in Chief Sinergie Italian Journal of Management

Full Professor of Management

Sapienza University of Roma - Italy

e-mail: alberto.pastore@uniromal.it

$$
\begin{array}{r}
\text { sinergie } \\
\text { italian journal of management } \\
\text { ISSN } 0393-5108 \\
\text { DOI } 10.7433 / \mathrm{s} 115.2021 .01 \\
\text { pp. } 11-14
\end{array}
$$

